\title{
Moving beyond Categorical Gender in Studies of Risk Aversion and Anxiety
}

\author{
Lena Wängnerud
}

University of Gothenburg

Maria Solevid

\section{University of Gothenburg}

\section{Monika Djerf-Pierre}

\section{University of Gothenburg}

Concepts such as risk aversion and anxiety have received renewed attention in various strands of gender and politics research. Most contemporary scholars suggest that gender gaps in this area are related to social norms and stem from social learning rather than from inherent gender traits. Very few, however, elaborate on the gender variable to reach a fuller understanding of the dynamics at work. In this study, we examined gender gaps in levels of anxiety, an area closely related to risk aversion, and we applied a combination of categorical measures of gender distinguishing between "woman, "man," and "other" and scales capturing grades of femininity and masculinity in individuals. We label this approach fuzzy gender, and we suggest that it can be used to advance research in our field. The key finding is an interaction effect between categorical measures of gender and fuzzy gender: The more female characteristics in women, the higher the levels of anxiety. Moreover, there is no difference in levels of anxiety between men and women with few female characteristics. The data used draw from a large-scale survey among Swedish citizens in 2013.

Keywords: sociotropic anxiety, egotropic anxiety, fuzzy gender, female characteristics, male characteristics 
7 he notion that women are more risk averse than men has received 1 renewed attention in various strands of gender and politics research. A prominent example is research on gender and corruption, where risk aversion is seen as a major explanation for the finding that higher proportions of women in parliament correlate with lower national levels of corruption (Esarey and Chirillo 2013; Esarey and Schwindt-Bayer 2017; Swamy et al. 2001). Risk aversion has also been identified as a mechanism that makes women more skeptical than men toward constitutional change (Verge, Guinjoan, and Rodon 2015). Most contemporary scholars have suggested that gender gaps in risk aversion are related to social norms and stem from social learning rather than from inherent gender traits. For example, Verge, Guinjoan, and Rodon $(2015,502)$ noted that gender gaps in risk attitudes "might not hold unconditionally." They linked heterogeneous effects across gender to characteristics of the issue studied, whether it is negatively or positively framed, and they concluded that negative framing magnifies initial differences - in this case the finding that women are more skeptical than men toward constitutional change. The explanation brought forward is that women's "uneasiness" (503) when anticipating negative outcomes is stronger than men's. We agree that social norms are important to study, but to increase understanding of the dynamics at work, one needs to further explore the emotions behind risk aversion, that is, to explore the phenomenon of anxiety.

Trait anxiety - neuroticism - is traditionally seen as a mechanism triggering risk aversion. ${ }^{1}$ The perceived vulnerability theses (see Satterfield, Mertz, and Slovic 2004) state that processes of social learning lead women, to a higher degree than men, to incorporate neuroticism as a facet of personality. The causal links between vulnerability, anxiety/ neuroticism, and risk aversion are, however, not totally clear, and in this article we delve into the question of how to explain gender gaps in anxiety. Our point of departure is that anxiety can be triggered by a variety of cues that the individual does not always recognize. One such cue may be founded on the female versus male body, and this, we argue,

1. Barlow $(2000,1249)$ suggests that fear is different from anxiety in that it works as an immediate emergency defense reaction, triggering a fight-or-flight response. Anxiety, on the other hand, focuses on possible - but not certain - future threats or negative events. The debate on anxiety, its duration (trait versus state anxiety), sources, and consequences is huge. Neuman et al. 2007 serves as a good introduction; here, we can only focus on major results from the literature on gender gaps in levels of anxiety. 
can be captured by a categorical measure of sex/gender. Another cue may, however, be founded on social norms of femininity versus masculinity and how individuals relate to these norms. To capture these norms, it is necessary to move beyond categorical ways of approaching the gender factor. The point we are making is that research on risk aversion and related phenomena should use a combination of categorical measures of sex/gender and scales capturing grades of femininity and masculinity to reach a fuller understanding of differences and similarities between men and women. Building on Tauchert (2002), we have used "fuzzy gender" as the term for the noncategorical measure of gender. ${ }^{2}$

Trait anxiety/neuroticism is included in the empirical analysis of this study, but the focus is on explanations for egotropic versus sociotropic anxiety, which, in comparison to trait anxiety, are more temporal emotional reactions. Egotropic anxiety relates to risks and threats in the individual's personal situation, such as being a victim of crime, and sociotropic anxiety relates to risks and threats to society at large, such as environmental degradation (Djerf-Pierre and Wängnerud 2016; Mutz 1994).

The novelty of this study lies in the introduction of a measurement that captures individuals' self-placement on two scales ranging from 0 ("few male/female characteristics") to 10 ("many male/female characteristics"), and the comparison of effects on levels of anxiety to the effects of a categorical measurement differentiating between "woman," "man," and "other" as well as a moderation analysis between the two. ${ }^{3}$ First, we show that the scales measuring fuzzy gender can reveal significant variation among respondents. Most women and men fit within an expected spectrum of each gender scale, but women do not unanimously choose the highest scores on the femininity scale, nor do men unanimously choose the highest scores on the masculinity scale. Second, when applied to the area of anxiety research, the key finding, apart from women persistently showing higher levels of anxiety, is an interaction effect: the more female characteristics in women, the higher the levels of anxiety. Moreover, there is no difference in level of anxiety between men and women with few female characteristics. The interaction effects are

2. In this article, we use the concepts "categorical sex/gender" versus "fuzzy gender" when referring to our own study. Indeed, the relationship between sex and gender is complicated, but the way we use these concepts will be clarified throughout the text. For the sake of simplicity, we use "gender" and "gender gaps" when referring to results in previous research.

3. That gender is a "fuzzy" concept is recognized in qualitative empirical studies (Ciccia and Verloo 2012; Lilliefeldt 2012), but to the best of our knowledge, this is the first time a fuzzy gender approach has been applied to a large-scale analysis of anxiety. 
valid for both egotropic and sociotropic anxiety. In conclusion, while men and women have different experiences with egotropic and sociotropic anxiety, for women, these experiences are amplified or suppressed, depending upon the degree to which they conform to "typical" constellations of feminine or masculine characteristics. ${ }^{4}$ Thus, our study underpins the notion of Verge, Guinjoan, and Rodon (2015) that gender differences in risk attitudes do not hold unconditionally. Whereas these researchers suggested elaborating on characteristics related to the issue studied, whether it is negatively or positively framed, we suggest a way to elaborate on the gender variable.

The article proceeds as follows: First, we review research on gender gaps in risk aversion and anxiety and clarify why it is especially pressing to move beyond categorical measures of sex/gender in this area. Next, we discuss strengths and weaknesses within current attempts to introduce noncategorical gender measures in large-scale survey studies and present our hypotheses. The section on methodology explains our measurement of fuzzy gender and discusses the variables included in the regression analysis. Because we introduce a new ${ }^{5}$ measure, the results section begins with a descriptive part; thereafter, we conduct a test of the relevance of the suggested measurement. Our main data source was a survey conducted by the SOM (Society, Opinion, and Media) Institute at the University of Gothenburg, Sweden. We also gathered data from a web panel study conducted by the Laboratory of Opinion Research (LORE) at the University of Gothenburg, which includes open-ended questions on femininity and masculinity that increase the complexity of how we understand the sources of anxiety. The final section discusses the extent to which the way we suggest distinguishing between categorical sex/gender and fuzzy gender is relevant for research on gender and politics more broadly.

\section{EXPLAINING GENDER GAPS IN RISK AVERSION AND LEVELS OF ANXIETY}

Bord and O'Connor $(1997,839)$ argued that women are more anxious than men about environmental risks and threats because they believe that such risks pose a direct health risk to themselves or to their families. Although

4. We thank an anonymous reviewer for suggesting a clearer way of expressing the main results.

5. The gender scales presented in this article were used previously in a survey from the SOM Institute at the University of Gothenburg (Nilsson and Holmberg 2006), but the results have thus far been published only in Swedish. 
many feelings of anxiety stem from actual experiences of threatening situations, gender scholars tend to emphasize that becoming a woman also entails learning to be "on guard" and to naturalize the fear of victimization. For example, research suggests that women feel more physically vulnerable to violence, such as rape, and that this sensitizes them to other risks as well (Hollander 2001, 2002; Slovic 1999). Moreover, scholars have suggested that women and men may attach different meanings to what appear to be the "same" risks, based on gendered practices and gendered ideologies with regard to social roles (Booth, Cardona-Sosa, and Nolen 2014; Gustafson 1998).

This blurred distinction between risk that is measureable and the feeling of risk (an emotional component) has encouraged scholars to explore the role of social norms. Esarey and Chirillo (2013) explored norms related to gender and risks in their research on corruption. They demonstrated that correlations between higher proportions of women in parliaments and lower levels of corruption are stronger in democracies than in authoritarian states and discuss how women, as a disadvantaged group in society, have stronger self-interest in following norms, because, owing to discrimination, they are likely to be punished more severely for transgressing them. Democracies contain a strong norm against corruption, and women are more perceptive of this norm than men; hence, a gender difference appears in democracies but not in authoritarian states. Verge, Guinjoan, and Rodon (2015) studied gendered norms within Spain, focusing on support for independence in Catalonia. Verge, Guinjoan, and Rodon departed from female and male voters' psychological dispositions toward risk-taking; they discussed how social roles such as female "uneasiness" and male "overconfidence" (Arch 1993; Niederle and Vesterlund 2007) may shape attitudes and behavior, making women more skeptical than men toward unpredictable situations such as independence. The study by Verge, Guinjoan, and Rodon (2015) built on experimental designs to tease out effects of issue framing, and the results show (516) that risk aversion shapes women's but not men's positions on independence, with negative treatment magnifying this pattern and positive treatment moderating, albeit not eliminating, it.

Our interest in moving beyond categorical ways of measuring gender stems from the fact that the strong relationship between gender and anxiety comes across as a robust finding (Bord and O'Connor 1997; Flynn, Slovic, and Mertz 1994; Slovic 1999; Slovic and Mertz 1994), and detailed studies (e.g., Djerf-Pierre and Wängnerud 2016) 
introducing measures on neuroticism in combination with ideology and values, political awareness, and news consumption, as well as variables such as age, education, income, parenthood, and immigrant status, have shown that initial gender gaps in levels of anxiety are reduced by the introduction of various explanatory factors, but a substantial part remains unexplained. Thus, the reason why gender gaps appear remains a conundrum, and to reach a fuller understanding of the role of social norms and expectations, it is necessary to elaborate on measurements of sex and gender.

\section{NONCATEGORICAL WAYS OF MEASURING GENDER IN LARGE-SCALE SURVEYS}

Large-scale social surveys have been slow in incorporating new, noncategorical, ways of measuring gender. Westbrook and Saperstein (2015) examined four of the largest and longest-running surveys in the United States and concluded that these surveys treat sex and gender as synonymous and thereby "continue to reproduce statistical representations that erase important dimensions of variation" (534). ${ }^{6}$ Scholars within the area of gender identity have developed instruments capturing gender in nuanced ways, and three prominent examples are the Bem Sex Role Inventory (BSRI), the Personal Attributes Questionnaire (PAQ), and the Sexual Identity Scale (SIS). Such instruments tend to list a large number of masculine and feminine characteristics, such as being "compassionate" or "aggressive," and respondents are asked to use scales to describe themselves according to these characteristics. ${ }^{7}$ One downside of this research, however, as indicated above, is that several of the most prominent measurements of noncategorical gender are resource intensive and therefore less attractive for many large-scale surveys in the social sciences. Moreover, Magliozzi, Saperstein, and Westbrook $(2016,3)$ noted that the BSRI and other similar instruments have been criticized for imposing definitions of femininity and masculinity on respondents by relying on gender stereotypes to assign scale scores (see also Connell 1995; Gill et al. 1987; Hoffman and Borders 2001).

6. Many scholars using large-scale surveys elaborate upon gender by including control variables (Hancock 2007), but see Hunt et al. (2007) and McLaughlin, Uggen, and Blackstone (2012) for exceptions.

7. See Palan, Areni, and Kiecker (1999) and Magliozzi, Saperstein, and Westbrook (2016) for a discussion of various instruments for measuring gender identity. 


\section{The Fuzzy-Gender Approach}

A fuzzy-logic approach is a fruitful way to capture social constructions of gender and how they may affect individuals' levels of anxiety. Tauchert (2002, 34) described fuzzy gender as an attempt to fill in the space between "naïve essentialism and hyper-constructivism." Thus, it rejects simplistic understandings of gender without going as far as radical deconstructionism, which rejects all attempts to distinguish between male and female bodies. A core assumption in the fuzzy gender approach is that individuals have a repertoire of category memberships that vary in relative overall importance in the self-concept and that people can self-categorize (Hogg, Terry, and White 1995, 260) to be, for example, more or less feminine and/or masculine. According to selfcategorization theory, people cognitively represent social groups such as gender in prototypes. Hogg, Terry, and White (261) pointed out that these prototypes are fuzzy sets that capture context-dependent features of group membership, often in the form of exemplary members, actual persons that typically represent the group, or ideal types that are more abstract representations. Thus, fuzzy gender is a concept related to socially constructed norms of femininity versus masculinity, norms that, to a varying degree, can be integrated into individuals' self-perceptions.

\section{Hypotheses}

Risk aversion indicates a behavioral component, whereas anxiety can be described as an emotion with potential behavioral consequences (Neuman et al. 2007). This study is rooted in the perceived vulnerability thesis, which says that women are more anxious than men about risks and threats because they generally feel more vulnerable in society (cf. Satterfield, Mertz, and Slovic 2004). Anxiety can be triggered by a variety of cues that the individual does not always recognize, and a full understanding of this phenomenon needs to take into consideration that these emotions may stem from multiple sources, such as socially constructed images of gender and also physical attributes.

In most societies, individuals make nearly automatic assessments about others' sex/gender (Magliozzi, Saperstein, and Westbrook 2016), and by the age of two and a half or three years, most children can "correctly" answer the question "Are you a boy or a girl?" (Egan and Perry 2001). Physical appearance matters in how individuals perceive the world. Previous research suggests that women, on average, feel more physically 
vulnerable to violence, such as rape, and that this sensitizes them to other risks as well (Slovic 1999). Thus, an experience of having a female body may produce higher levels of anxiety among women, and this, we assume, can be captured by a categorical measure of sex/gender. Following this line of reasoning, we hypothesize that

H1: Women will display higher levels of anxiety than men.

This hypothesis, that women display higher levels of anxiety than men, has been confirmed in a plethora of studies. Through the introduction of fuzzy gender, we aim to further examine the effects of socially constructed images of gender. Feminist researchers argue that women's higher levels of anxiety, specifically the fear of violence and crime, act as a form of social control that prevents women from achieving political and economic equality (Hollander 2001, 2002). Along this line of reasoning, we hypothesized that vulnerability stems not only from sources related to actual situations but also from sources related to norms and expectations. Not least, media and culture - ads, newspapers, magazines, films, et cetera - produce images that portray women as "weak" and men as "strong" and capable of handling events (see Edström and Jacobsson 2015 for a recent quantitative study). ${ }^{8}$ We believe that such images influence, in a given context, the set of available gender prototypes and that self-categorization, the process in which individuals assess themselves in relation to such prototypes, is a cognitive process with attitudinal and behavioral consequences. Thus, we expected that strong self-identification with feminine versus masculine characteristics is linked to anxiety levels typical for each gender group:

H2: The more feminine characteristics in an individual, the higher the level of anxiety.

H3: The more masculine characteristics in an individual, the lower the level of anxiety.

There are also reasons to expect interaction effects between categorical sex/ gender and fuzzy gender. This expectation represents the idea that sex and social constructions of gender, while not overlapping, are interlinked. We believe that individuals of a certain sex are particularly perceptive of culturally produced images of that sex, and thus, we hypothesize that

8. The literature on gender stereotypes - sources and consequences - is rich. Ellemers (2018) presents an overview of psychology-oriented research. Eagly and Steffen (1984) is a classic study arguing that gender stereotypes stem from the distribution of women and men into social roles. 
H4: The more feminine characteristics in women, the higher the levels of anxiety.

H5: The more masculine characteristics in men, the lower the levels of anxiety.

Our empirical analyses include two indicators of anxiety: the Sociotropic Anxiety Index (SAI), which taps into anxiety about developments in society at large, and the Egotropic Anxiety Index (EAI), which taps into anxiety related to the personal situation (Djerf-Pierre and Wängnerud 2016). These indexes are designed to capture generalized feelings of unpredictability and uncontrollability regarding future risks and threats (Barlow 2000). We included both indexes to reach stability in the results; we expect the same effects regardless of which index we use as the dependent variable.

\section{DATA AND METHODOLOGY}

The main data source for this study is the 2013 survey conducted by the SOM Institute at the University of Gothenburg, Sweden. The survey was sent to 3,400 respondents randomly selected from the census register. Both Swedish citizens and non-Swedish citizens living in Sweden are included in the sample (University of Gothenburg, SOM-Institute). The response rate was $52 \%$, and the distribution of responses matches the proportion of the Swedish population with regard to gender, social class, and education, but younger people and respondents with an immigrant background are underrepresented (Vernersdotter 2014). In addition, we used data from a web panel, also from 2013, run by LORE (http://www.lore.gu.se) at the University of Gothenburg. The respondents in the web panel were mainly self-recruited, and there is an overrepresentation of respondents with higher education and high levels of political interest. The LORE data were used to validate perceptions of what female and male characteristics contain, a procedure helpful in the interpretation of the results reached in the cross-sectional survey of the general Swedish population.

\section{Independent Variables}

First, we used a traditional way of measuring sex/gender in which respondents are able to choose between "woman" and "man" and the category "other." The survey question capturing fuzzy gender reads: Sometimes, one talks about individuals having both female and male 
characteristics. To what extent would you say that you have female and male characteristics, respectively? Following fuzzy logic, answers were given on 11-point scales where $0=$ "I have few such characteristics" and $10=$ "I have many such characteristics." Respondents could choose any combination of male and female characteristics; male and female were not posed as opposite ends on a single scale. In addition, no definitions included male/female characteristics. In this way, we opened the possibility of context-dependent features of group membership allowing for a mix of male and female characteristics (Hogg, Terry, and White 1995; Huddy 2001; Magliozzi, Saperstein, and Westbrook 2016). We were guided by the following principles in the operationalization of fuzzy gender: (a) it should be possible to choose more than one identity, (b) there should be gradations in identity strength, and (c) the measurement should be comparatively simple. The web panel survey also included the two fuzzy-gender scales, identical to those in the SOM survey, but it added an open-ended question in which respondents were asked to write down what they viewed as male and female characteristics when answering the fuzzy gender question. This generated answers by 1,528 respondents. We coded the answers using a bottom-up technique in which a detailed coding scheme, for the purpose of this study, resulted in a number of overarching themes, such as care, empathy, strength and self-sufficiency (see Appendix 1).

\section{Dependent Variables}

In this study, we relied on self-reported feelings of worry as the operational definition of anxiety (see Djerf-Pierre and Wängnerud 2016 for a similar approach). ${ }^{9}$ The SAI is an additive index of 11 variables measuring anxiety toward different social risks and threats. The risks and threats included terrorism, environmental degradation, economic crisis, religious conflicts, unemployment, organized crime, social cleavages, increasing alcohol consumption, global epidemics, climate change, and increasing drug use. The question asked was "In the present situation, what worries you most about the future?" The level of worry was measured as 1 , "not at all worried"; 2, "not so worried"; 3, "moderately worried"; and" 4, "very worried." The index was constructed by adding the individual scores for

9. Anxiety is the concept most often used in the literature we refer to. The survey we build on is in Swedish, and most studies in Swedish on this topic use "worry" as an operational definition of anxiety. A more direct translation from English would lead to a term that connotes "angst." 
each of the risks/threats, and respondents with valid answers on at least nine items were included in the index. After rescaling, the index ranged from 1 ("not at all worried about any risks") to 4 ("very worried about all risks"). The SAI results show a mean of 2.94 and a standard deviation of .57. The Cronbach's $\alpha$ for the index is .81. The EAI is, like the SAI, an additive index. The EAI is based on five questions on how worried the individual is about his/her own personal situation: "If you consider your own personal situation, what worries you most about the future?" The question was posed with regard to five different conditions: "lacking money when faced with an unexpected expense," "not getting a large enough pension," "becoming unemployed," "being struck by serious illness," and "being the victim of a crime." The response alternatives ranged, like the SAI, from 1 ("not at all worried") to 4 ("very worried"). The items involve negative conditions that are common enough to be relevant to most individuals but specific enough to target different dimensions of negative circumstances (see Satterfield, Mertz, and Slovic 2004). The additive index was constructed by adding the individual's scores, and we included only the respondents who answered a minimum of four of five questions. Finally, the index was rescaled to range from 1 ("not worried about any of the conditions") to 4 ("very worried about all the conditions"). The index has a mean of 2.43 and standard deviation of .67. We detected a correlation between items:, if a person worries about being affected by one negative condition, that person also tends to worry about the others. The Cronbach's $\alpha$ for the five indicators is .78.

\section{Control Variables}

To account for issues of spuriousness and redundancy, we included additional variables known for their relationship with anxiety in general and also known for reducing, without removing, the effect of sex/gender on anxiety in particular (Djerf-Pierre and Wängnerud 2016). Thus, we included age, education, household income, immigrant status, personality traits, ${ }^{10}$ general self-confidence, news consumption, interest in politics, and ideological left-right position as control variables (see Appendix 1 for wording and coding of questions).

10. The decision to include personality traits as control variables is based on our previous work examining differences in sociotropic anxiety between women and men (see Djerf-Pierre \& Wängnerud, 2016). Thus, we have chosen to continue with regression models that are as comparable as possible. The results presented in the current study (Tables 1 and 2 ) are robust when the personality trait variables are excluded. 


\section{Structure of the Empirical Analysis}

Because we are introducing a less established way of measuring noncategorical gender, we begin by describing variation in femininity and masculinity among Swedish citizens. This was our first test of the relevance of a fuzzy gender approach: If respondents clustered around endpoints or used only one or two points on each scale, then our suggested measurement would have limited value. We then tested the relevance of this way of operationalizing fuzzy gender by applying it as an independent variable in regression analyses of levels of anxiety.

\section{FUZZY GENDER AMONG SWEDISH CITIZENS}

Sweden is considered one of the most gender-equal countries in the world and it is often found at the top of international rankings of gender equality. ${ }^{11}$ Public policies encourage "fluid" gender roles through measures such as having nontransferable days in the parental-leave system, which encourages fathers to stay at home with small children. Mothers are encouraged to take active part in the labor market through policies such as separate income tax and low fees for public childcare. Rankings from various LGBTQ organizations also tend to single out Sweden as comparatively supportive of nontraditional values and lifestyles, for example, through same-sex marriage legislation that is equal to the legislation for marriages between women and men. ${ }^{12}$ From that perspective, it was a bit surprising to find that only 1 of 1,768 respondents in the SOM survey selected the category "other" for the more traditional categorical way of measuring sex/gender. The resulting fuzzy-gender scale, however, displays a nuanced pattern. Figure 1 shows self-placement by Swedish women and men on the femininity scale ranging from 0 ("few female characteristics") to 10 ("many female characteristics").

11. See, for example, The Global Gender Gap Report 2016 from the World Economic Forum, where Sweden is ranked among the top four most gender-equal countries in the world (http://www3.weforum. org/docs/GGGR16/WEF_Global_Gender_Gap_Report_2016.pdf). This same result is reported in the ranking from Social Watch (http://www.socialwatch.org/node/14367).

12. Statistics Sweden (SCB) regularly publishes data on gender equality in Sweden. See Women and Men in Sweden: Facts and Figures 2014 for information in English (http://www.scb.se/Statistik/_ Publikationer/LE0201_2013B14_BR_X10BR1401ENG.pdf). Sweden introduced same-sex marriage in 2009. For rankings of countries regarding LGBTQ rights, see, for example, Rainbow Europe (https://rainbow-europe.org/country-ranking) or Equaldex (http://www.equaldex.com/compare/ sweden). 
On one hand, Figure 1 shows that most women (solid line) tended to choose values on the upper part of the femininity scale, and most men (dashed line) tended to choose values on the lower part; the two lines cross at the value of 6 . The value of 5 is the most common value among men, whereas 8 and 10 are the most common values among women. More interesting perhaps is to look at mean values: the mean for women on the femininity scale is 7.77 , and for men, 3.47. On the other hand, substantial numbers that deviate from the more traditional and expected patterns: among women, $21 \%$ chose values between 0 and 6 , and among men, 20\% chose values between 6 and 10 (Figure 1). But the most extreme values $(0-2$ for women and $9-10$ for men) were very seldom chosen.

Figure 2 shows self-placement by Swedish women and men on the masculinity scale ranging from 0 (few male characteristics) to 10 (many male characteristics). Interestingly, Figure 1 and Figure 2 mirror each other. In Figure 2, the results display rather expected patterns: most men (dashed line) tended to choose values on the upper part of the scale and most women (solid line) tended to choose values on the lower part, and the two lines cross at the value of 6 . The value of 5 is the most common value among women, whereas 8 is the most common value among men. The mean value for men on the masculinity scale is 7.85 (which is a bit higher than for women on the femininity scale), and for women, 3.61 (which also is a bit higher than for men on the femininity scale). Figure 2 resembles Figure 1 also in the respect that the most extreme values $(0-2$ for men and 9-10 for women) were very seldom chosen. What is not displayed in Figures 1 and 2 is the combination of the two scales. Cross tabulations of answers show that $7 \%$ of the population have low scores on both scales $(5$ and under), which indicates that they reject both male and female characteristics, and 14\% have high scores on both scales (6 and higher), which indicates that they perceive themselves to have both many female and many male characteristics.

To further validate our findings from the cross-sectional survey, we also asked open-ended questions about female and male characteristics in a web-based panel. The findings show that $16 \%$ of respondents explicitly rejected the idea of male/female characteristics or mentioned norms, social constructions, prejudices, or culture when asked to write down what they were thinking of when using the two scales. A substantial number of respondents, $12 \%$, explicitly referred to physical/biological differences between women and men or linked their answers to statements such as "I'm a woman," "I'm a man," or "My mother/father is." When coding the answers, we noted huge variation in perceptions of 


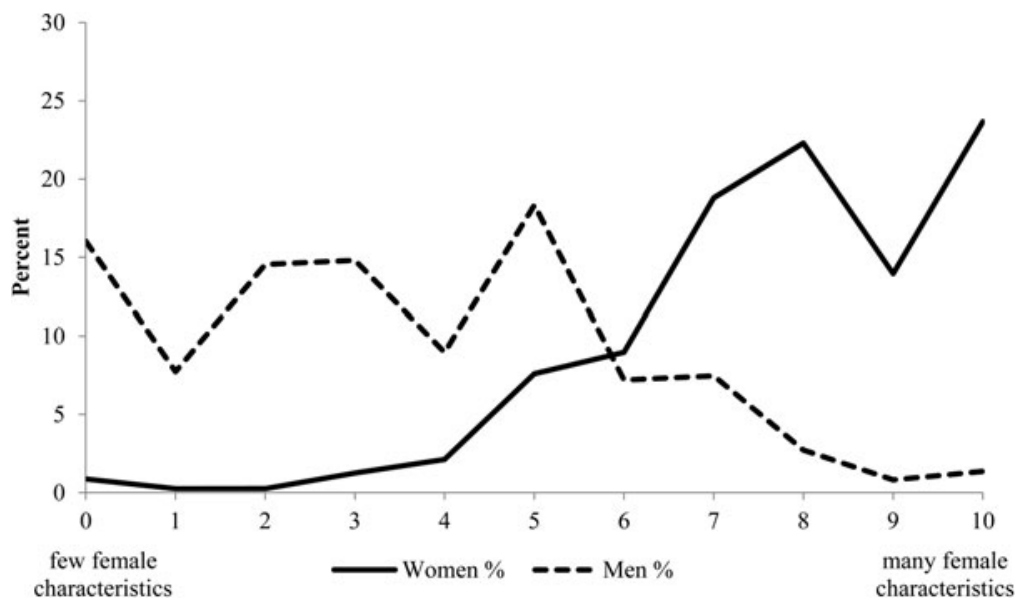

Figure 1. Self-placement by Swedish women and men on a femininity scale ranging from 0 , "I have few female characteristics," to 10 , "I have many female characteristics" (\%).

Source: The National SOM survey 2013, University of Gothenburg. Comment: See main text and Appendix 1 for question wording.

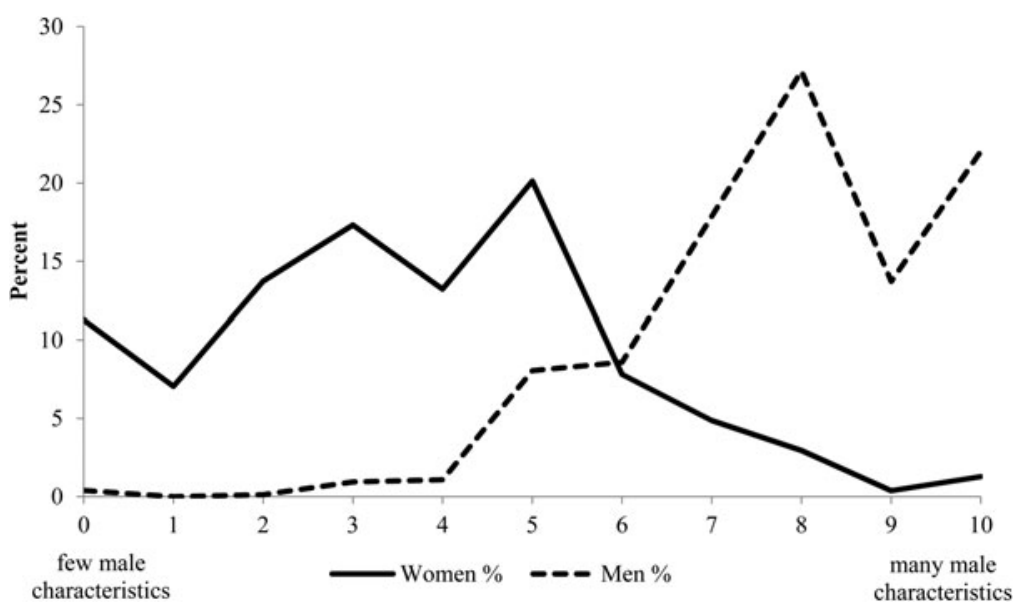

FIGURE 2. Self-placement by Swedish women and men on a masculinity scale ranging from 0 , "I have few male characteristics," to 10 , "I have many male characteristics" (\%).

Source: The National SOM survey 2013, University of Gothenburg. Comment: See main text and Appendix 1 for question wording. 
male and female characteristics, but at the same time, answers could be grouped under six more overarching headings: care, empathy, strength, energy/drive, self-sufficiency, and practical knowledge. Interestingly, none of the overarching categories was used solely for male or female characteristics. The dominant categories in answers referring to the scales align, however, with rather traditional conceptions: care and empathy for the femininity scale and self-sufficiency and strength for the masculinity scale (see Table A3 in Appendix 2).

\section{EXAMINING EFFECTS ON LEVELS OF ANXIETY}

We tested the relevance of our suggested measurements in an area anxiety research - where existing gender gaps are hard to fully explain by factors such as neuroticism, ideology and values, political awareness, news consumption, or other social background characteristics such as age, education, income, and immigrant status (Djerf-Pierre and Wängnerud 2016). First, we report the direct effects of the categorical sex/gender and fuzzy gender on egotropic and sociotropic anxiety, respectively, followed by models in which categorical sex/gender and fuzzy gender were interacted. We display five regression models without control variables (models $1-5$ in Tables 1 and 2) and five regression models with all control variables (models $6-10$ in Tables 1 and 2). We deliberately put tough control variables in models 6-10 to ensure that the obtained results were robust, but with that said, the control variables are indeed of minor interest, and therefore, we report abbreviated tables. Full tables, including coefficients for the control variables, are provided in Appendix 2 (see Tables Al and A2). ${ }^{13}$

Our first hypothesis was that women would display higher levels of anxiety than men and that this would be the case for both egotropic and sociotropic anxiety. Without control variables, women were, on average, .251 index points more worried about personal issues (model 1 in Table 1) and .208 points more worried about societal issues (model 1 in

13. Tables $\mathrm{Al}$ and $\mathrm{A} 2$ in the appendix also include two regression models (model 11 and model 12 ) in which the interaction terms woman $\times$ female characteristics and woman $\times$ male characteristics are simultaneously included. The main conclusions are not altered, although the interaction women $x$ female charcteristics just falls below a p-value of .10. That the general conclusion holds is further illustrated in Figures $\mathrm{Al}$ and $\mathrm{A} 2$, which compare the predicted levels of egotropic and sociotropic anxiety, respectively, among women and men with varying degrees of female characteristics from models with one interaction term (woman $\times$ female characteristics) and models with the two interactions terms, as described above. 
Table 1. Effects of categorical sex/gender and fuzzy gender on egotropic anxiety (OLS, unstandardized coefficients, standard errors in parentheses)

\begin{tabular}{|c|c|c|c|c|c|c|c|c|c|c|}
\hline & \multicolumn{10}{|c|}{ Dependent variable: Egotropic Anxiety Index $(1-4,4=$ Very worried $)$} \\
\hline & Model 1 & Model 2 & Model 3 & Model 4 & Model 5 & Model 6 & Model 7 & Model 8 & Model 9 & Model 10 \\
\hline Woman & $\begin{array}{l}0.251^{\text {䄅篎 }} \\
(0.038)\end{array}$ & & $\begin{array}{l}0.220 \text { 前社 } \\
(0.062)\end{array}$ & $\begin{array}{l}0.106 \\
(0.132)\end{array}$ & $\begin{array}{l}0.399 * * \\
(0.148)\end{array}$ & $\begin{array}{l}0.168^{\text {米和 }} \\
(0.037)\end{array}$ & & $\begin{array}{l}0.164^{* * *} \\
(0.057)\end{array}$ & $\begin{array}{l}-0.076 \\
(0.123)\end{array}$ & $\begin{array}{l}0.378^{* * *} \\
(0.143)\end{array}$ \\
\hline $\begin{array}{l}\text { Female characteristics } \\
(0-10,10=\text { Many })\end{array}$ & & $\begin{array}{l}0.014 \dagger \\
(0.009)\end{array}$ & $\begin{array}{l}0.001 \\
(0.009)\end{array}$ & $\begin{array}{l}-0.005 \\
(0.011)\end{array}$ & $\begin{array}{l}0.004 \\
(0.009)\end{array}$ & & $\begin{array}{l}0.022^{* * *} \\
(0.008)\end{array}$ & $\begin{array}{l}0.013 \\
(0.009)\end{array}$ & $\begin{array}{l}-0.001 \\
(0.011)\end{array}$ & $\begin{array}{l}0.015 \dagger \\
(0.009)\end{array}$ \\
\hline $\begin{array}{l}\text { Male characteristics } \\
\quad(0-10,10=\text { Manv })\end{array}$ & & $\begin{array}{l}-0.026^{\text {* }} \\
(0.009)\end{array}$ & $\begin{array}{l}-0.006 \\
(0.011)\end{array}$ & $\begin{array}{l}-0.006 \\
(0.011)\end{array}$ & $\begin{array}{l}0.013 \\
(0.018)\end{array}$ & & $\begin{array}{l}-0.003 \\
(0.009)\end{array}$ & $\begin{array}{l}0.012 \\
(0.010)\end{array}$ & $\begin{array}{l}0.013 \\
(0.010)\end{array}$ & $\begin{array}{l}0.035^{*} \\
(0.017)\end{array}$ \\
\hline Woman $\times$ Female characteristics & & & & $\begin{array}{l}0.018 \\
(0.019)\end{array}$ & & & & & $\begin{array}{l}0.039^{*} \\
(0.018)\end{array}$ & \\
\hline Woman $\times$ Male characteristics & & & & & $\begin{array}{l}-0.029 \\
(0.021)\end{array}$ & & & & & $\begin{array}{l}-0.034 \\
(0.021)\end{array}$ \\
\hline Control variables in the model & $\mathrm{NO}$ & $\mathrm{NO}$ & $\mathrm{NO}$ & $\mathrm{NO}$ & $\mathrm{NO}$ & YES & YES & YES & YES & YES \\
\hline Constant & 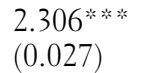 & 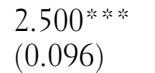 & $\begin{array}{l}2.351^{\text {米的 }} \\
(0.104)\end{array}$ & $\begin{array}{l}2.369 \text { **; } \\
(0.105)\end{array}$ & 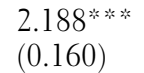 & $\begin{array}{l}2.364^{* * \cdots *} \\
(0.157)\end{array}$ & $\begin{array}{l}2.343 \text { 皮的 } \\
(0.177)\end{array}$ & 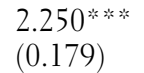 & 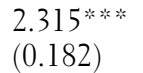 & 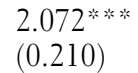 \\
\hline Observations & 1200 & 1200 & 1200 & 1200 & 1200 & 1200 & 1200 & 1200 & 1200 & 1200 \\
\hline$R 2$ & 0.035 & 0.025 & 0.036 & 0.036 & 0.037 & 0.226 & 0.222 & 0.227 & 0.230 & 0.229 \\
\hline
\end{tabular}

Source: The Swedish National SOM survey 2013. Comment: $\uparrow p \leq 0.1,{ }^{*} p \leq 0.05,{ }^{* *} p \leq 0.01,{ }^{* * * *} p \leq 0.001$. OLS, ordinary least squares. See main text and Appendix 1 for question wording and coding. See Appendix 2 for full tables. 
Table 2. Effects of categorical sex/gender and fuzzy gender on sociotropic anxiety (OLS, unstandardized coefficients, standard errors in parentheses)

Dependent variable: Sociotropic Anxiety Index (1-4, 4 = Very worried)

\begin{tabular}{|c|c|c|c|c|c|c|c|c|c|c|}
\hline & Model 1 & Model 2 & Model 3 & Model 4 & Model 5 & Model 6 & Model 7 & Model 8 & Model 9 & Model 10 \\
\hline Woman & 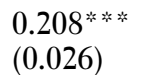 & & 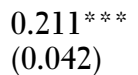 & $\begin{array}{l}-0.002 \\
(0.087)\end{array}$ & $\begin{array}{l}0.415^{\text {***; }} \\
(0.098)\end{array}$ & $\begin{array}{l}0.169^{\text {**; }} \\
(0.026)\end{array}$ & & 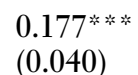 & $\begin{array}{l}0.054 \\
(0.085)\end{array}$ & $\begin{array}{l}0.244^{*} \\
(0.098)\end{array}$ \\
\hline $\begin{array}{r}\text { Female characteristics } \\
(0-10,10=\text { Many) }\end{array}$ & & $\begin{array}{l}0.009 \\
(0.006)\end{array}$ & $\begin{array}{l}-0.004 \\
(0.006)\end{array}$ & $\begin{array}{l}-0.016^{\text {* }} \\
(0.008)\end{array}$ & $\begin{array}{l}-0.001 \\
(0.006)\end{array}$ & & $\begin{array}{l}0.014^{*} \\
(0.006)\end{array}$ & $\begin{array}{l}0.004 \\
(0.006)\end{array}$ & $\begin{array}{l}-0.003 \\
(0.008)\end{array}$ & $\begin{array}{l}0.005 \\
(0.006)\end{array}$ \\
\hline $\begin{array}{l}\text { Male characteristics } \\
(0-10,10=\text { Many })\end{array}$ & & $\begin{array}{l}-0.021^{\text {** }} \\
(0.006)\end{array}$ & $\begin{array}{l}-0.003 \\
(0.007)\end{array}$ & $\begin{array}{l}-0.002 \\
(0.007)\end{array}$ & $\begin{array}{l}0.019 \\
(0.012)\end{array}$ & & $\begin{array}{l}-0.009 \\
(0.006)\end{array}$ & $\begin{array}{l}0.006 \\
(0.007)\end{array}$ & $\begin{array}{l}0.007 \\
(0.007)\end{array}$ & $\begin{array}{l}0.013 \\
(0.012)\end{array}$ \\
\hline Woman $\times$ Female characteristics & & & & $\begin{array}{l}0.035^{\text {\% }} \\
(0.012)\end{array}$ & & & & & $\begin{array}{l}0.020 \dagger \\
(0.012)\end{array}$ & \\
\hline Woman $\times$ Male characteristics & & & & & $\begin{array}{l}-0.033^{\text {* }} \\
(0.014)\end{array}$ & & & & & $\begin{array}{l}-0.011 \\
(0.014)\end{array}$ \\
\hline Control variables in the model & $\mathrm{NO}$ & $\mathrm{NO}$ & $\mathrm{NO}$ & NO & NO & YES & YES & YES & YES & YES \\
\hline Constant & $\begin{array}{l}2.843^{* * * * *} \\
(0.018)\end{array}$ & $\begin{array}{l}3.019 * * * * \\
(0.064)\end{array}$ & 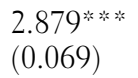 & $\begin{array}{l}2.911 \text { 米粠 } \\
(0.070)\end{array}$ & 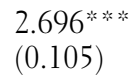 & $\begin{array}{l}2.358^{* * * * * x^{*}} \\
(0.110)\end{array}$ & $\begin{array}{l}2.406^{\text {***; }} \\
(0.125)\end{array}$ & $\begin{array}{l}2.306^{* * * * *} \\
(0.126)\end{array}$ & $\begin{array}{l}2.340 * \text { *** } \\
(0.127)\end{array}$ & 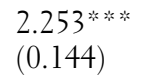 \\
\hline Observations & 1261 & 1261 & 1261 & 1261 & 1261 & 1261 & 1261 & 1261 & 1261 & 1261 \\
\hline R2 & 0.049 & 0.031 & 0.050 & 0.056 & 0.054 & 0.175 & 0.163 & 0.176 & 0.177 & 0.176 \\
\hline
\end{tabular}

Source: The Swedish National SOM survey 2013. Comment: $\uparrow p<=0.1,{ }^{*} p<=0.05,{ }^{* * *} p<=0.01,{ }^{* * * *} p<=0.001$. OLS, ordinary least squares. See main text and Appendix 1 for question wording and coding. See Appendix 2 for full tables. 
Table 2). Adding all the control variables slightly reduced the effect of categorical sex/gender on anxiety. All else being equal, women displayed .168 index points greater egotropic anxiety (model 6 in Table 1) and .169 index points greater sociotropic anxiety than men (model 6 in Table 2). Thus, $\sim 67 \%$ and $81 \%$ of the difference between women's and men's levels of egotropic anxiety and sociotropic anxiety, respectively, remain under control for other variables (including neuroticism). The results were robust even when the fuzzy-gender scales were included in the regression models (model 8 in Tables 1 and 2). Thus, not surprisingly, $\mathbf{H l}$ is confirmed.

Regarding the second hypothesis, that individuals with more female characteristics are more anxious, we identified an initial weak positive effect of female characteristics, indicating that anxiety is higher among those who identify themselves as having more female characteristics. We also detected a weak negative effect of male characteristics, which indicates less anxiety among those who identify as having many male characteristics, for both egotropic and sociotropic anxiety (model 2 in Tables 1 and 2) when other variables were not included. However, the effects of the two fuzzy gender scales washed out when the categorical measures of sex/gender were included (model 3 in Tables 1 and 2). Without categorical sex/gender, but under control for age, education, household income, immigrant background, self-confidence, personality, interest in politics, news consumption, and ideology, we detected a weak, significant positive effect of female characteristics on both egotropic and sociotropic anxiety (model 7 in Tables 1 and 2). Comparing an individual with few female characteristics (variable value 0 ) and an individual with many female characteristics (variable value 10) yields a maximum difference of roughly .20 index units $(0.022 \times 10$ and $0.014 \times 10)$ more egotropic or sociotropic anxiety for the individual with many female characteristics. However, as in model 3, the effect of female characteristics vanished when we also entered the categories man/woman into the models (model 8 in Table 1 and Table 2). We found no direct effect of male characteristics, in either model 7 (without categorical sex/gender) or model 8 (with categorical sex/gender) in Tables 1 and 2. In sum, female characteristics do seem to produce slightly higher levels of egotropic and sociotropic anxiety, but only when the categorical measure of sex/gender is left out of the regression model. Thus, $\mathbf{H} 2$ is partly confirmed. We found no support for $\mathbf{H} 3$, that is, more masculine characteristics did not yield lower levels of anxiety. 
The main contribution of this study, however, is the test of a presumed interaction between categorical sex/gender and fuzzy gender. As spelled out in $\mathbf{H 4}$, we expected more feminine characteristics in women to be associated with higher levels of anxiety, and consequently, we also expected more masculine characteristics in men to be associated with lower levels of anxiety (H5). We entered the interaction terms between women and female characteristics (model 4 in Tables 1 and 2) and women and male characteristics (model 5 in Tables 1 and 2) into two different models, both including the two fuzzy-gender scales. ${ }^{14}$ Without any control variables, there was only a significant interaction effect between categorical sex/gender and fuzzy gender on sociotropic anxiety (models 4 and 5 in Table 2). In short, these more simple models show that sociotropic anxiety increases among women the more female characteristics they identify with. In addition, our results also show that levels of anxiety do not differ between women and men with many male characteristics; this is a result of women becoming slightly less anxious and men becoming slightly more anxious the more male characteristics they perceive. When including the control variables, we detected a weak significant interaction effect of female characteristics for both egotropic (model 9 in Table 1) and sociotropic anxiety among women (model 9 in Table 2), but no significant interaction effect of male characteristics among men remained (model 10 in Tables 1 and 2). To further illustrate the results, the significant interactions are shown in the two figures below. In Figure 3, there is no difference in levels of egotropic anxiety between men and women with few female characteristics. However, the higher the degree of female characteristics in women, the higher the level of egotropic anxiety, but we did not identify any difference among men. The results for sociotropic anxiety are even more distinct (Figure 4). Once again, at low levels of female characteristics, there is no significant difference in sociotropic anxiety between men and women. Moreover, the higher the level of female characteristics, the higher the level of sociotropic anxiety among women. In sum, we find support for $\mathbf{H 4}$, demonstrating that fuzzy gender indeed adds to the explanation of gender differences in feelings of anxiety, both with regard to the personal situation as well as for societal issues. We do not find any support for $\mathbf{H 5}$, that is, men with many male characteristics are not less 


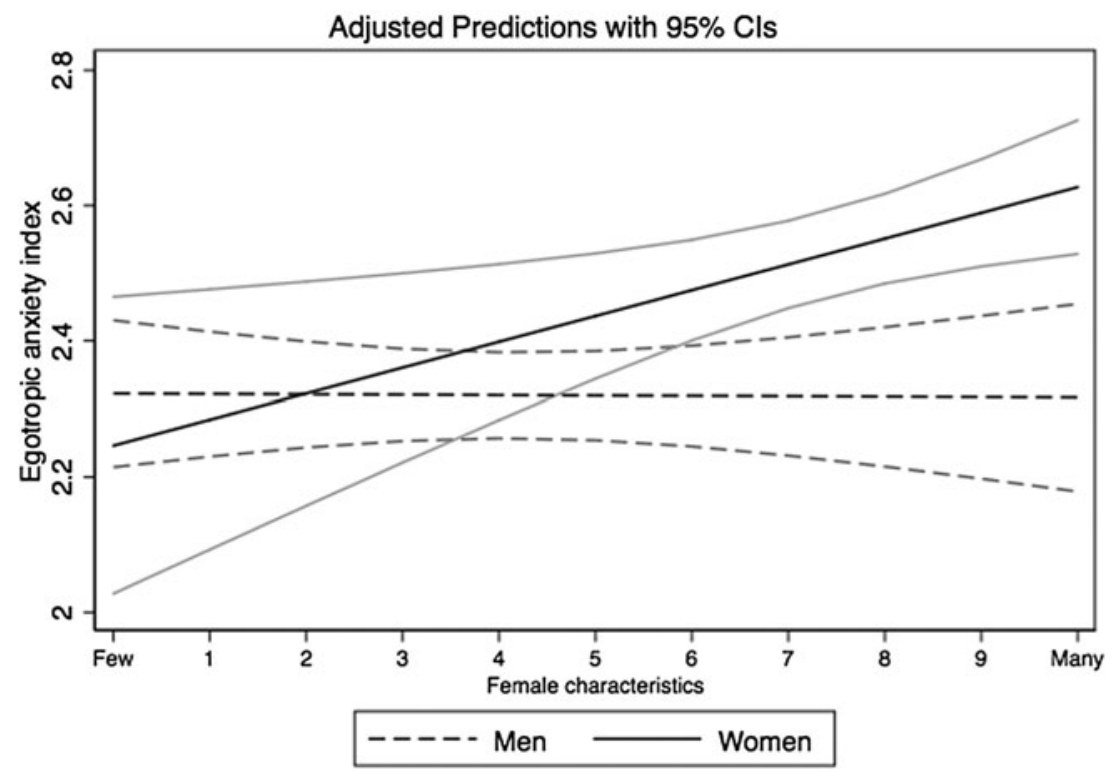

FIGURE 3. Predicted effects of female characteristics on egotropic anxiety among men and women.

Comment: Predictions calculated based on model 9, Table 1. All other variables held at their means. CIs, confidence intervals.

anxious. In addition, the obtained effects in general are small but nonetheless substantive, given the tough control variables included.

\section{DISCUSSION AND CONCLUSION}

The main finding of this article is that fuzzy gender matters to some extent in understanding the differences in anxiety levels, but the effects are conditional on categorical sex/gender. Women with many female characteristics are more anxious regarding both their personal situations and the societal situation. Equally important, we found no difference in levels of egotropic or sociotropic anxiety between men and women who identify as having fewer female characteristics. In line with results in the study on risk aversion by Verge, Guinjoan, and Rodon (2015, 516), effects of sex/gender, measured in conventional ways, were modified but not eliminated in our study. Because a persistent gender gap remains, it would be a mistake to leave out traditional measures of sex/gender, 


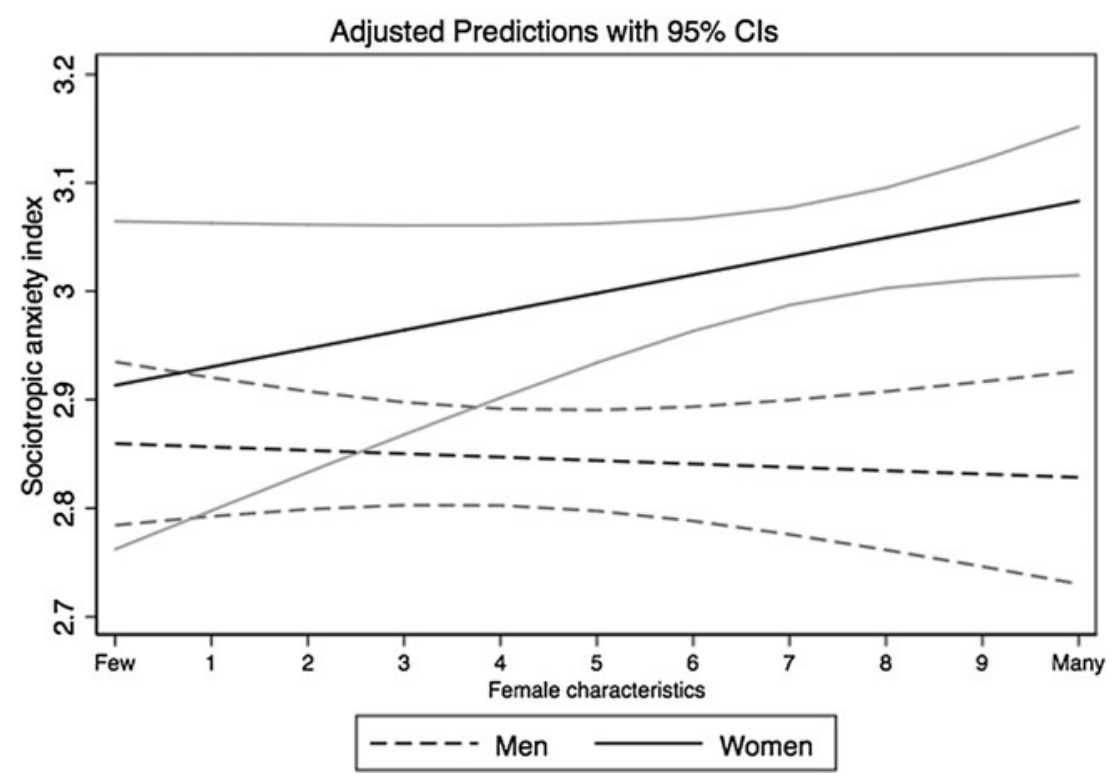

FIGURE 4. Predicted effects of female characteristics on sociotropic anxiety among men and women.

Comment: Predictions calculated based on model 9, Table 2. All other variables held at their means. CIs, confidence intervals.

distinguishing between men and women, in research on anxiety and related areas.

Our results confirm that men are less anxious than women, but in the regression analyses, the masculinity scale did not add any explanatory power. Core features of a masculine prototype in contemporary Sweden are, according to the open-ended question on male and female characteristics in the web panel by LORE, self-sufficiency and strength. Verge, Guinjoan, and Rodon (2015, 503) discussed how men's overconfidence may cancel out the impact of risk, and the findings (a) that masculinity scales do not add explanatory power in the analysis of anxiety (our study) and (b) that men's attitudes and behavior are only slightly shaped by risk aversion (Verge Guinjoan, and Rodon 2015) should be explored further. In countries such as Sweden and Spain, which pride themselves on gender equality, ${ }^{15}$ men may still be socialized into a culture where risks are downplayed and feelings of anxiety are

15. For Sweden, see note 11; for Spain, see Verge 2012. 
suppressed. An alternative explanation could be that mainstream media and culture produce and reinforce female stereotypes to a larger extent than male stereotypes, and thus, the social pressure on women to internalize "feminine" characteristics is particularly strong and leads to the pattern detected in our data.

Returning to our main finding that the more female characteristics in women, the higher the levels of anxiety, and connecting the finding to our discussion in the theory section, we argue that this finding pertains to vulnerability and feelings triggered both by cues related to physical appearance and to social constructions of femininity. Because we used cross-sectional data, we were not able to draw conclusions on causality. One possible interpretation, based on answers to the open-ended question in the web panel, is, however, that the mechanism at work is prosocial behavior (Dovidio et al. 2006; Eagly 2009) because care and empathy are, in contemporary Sweden, core features of a feminine prototype. We believe that female care for people - children, relatives, friends, and so forth - also extends to care for developments in society at large. Thus, we strengthen previous research highlighting care, and not only neuroticism, as a mechanism triggering risk aversion (see Bord and O'Connor 1997).

A final theme is how our study contributes to an ongoing debate on how to improve measurements of sex and gender. The scales of femininity and masculinity used in this article are useful also in studies outside the area of anxiety and risk aversion. ${ }^{16}$ The suggested measurements are comparatively simple, and other scholars are currently moving in the same direction (e.g., Magliozzi, Saperstein, and Westbrook 2016; Westbrook and Saperstein 2015). These types of measurements and data allow for nuanced studies of gender fluidity across time and across groups. Again, from the perspective of gender fluidity, there are no differences in levels of anxiety between women and men with few female characteristics, and this result was stable across both anxiety indexes. Moreover, the results from cross tabulations of answers showed that almost 1 in 10 reject both male and female characteristics, and an even larger group perceive themselves to have both many female and many male characteristics. Taken together,

16. A recent study of the different effects of sex and gender on politically relevant matters is that of Hatemi et al. (2012). The conclusion reached (89-90) is that for some issues, such as attitudes toward reproduction, family leave, and child care, the sex of respondents is important, but for more "transient socially defined issues" such as gay pride parades, one's gender identity is a better predictor. In this study, however, the measurement of gender is rather complex. 
the results indicate that these two less "typical" groups make up a fifth of the Swedish population.

\section{SUPPLEMENTARY MATERIAL}

To view supplementary material for this article, please visit https:/doi.org/ $10.1017 / \mathrm{S} 1743923 \mathrm{X} 18000648$

\section{REFERENCES}

Arch, E. C. 1993. "Risk-Taking: A Motivational Basis for Sex Differences." Psychological Reports 73 (1): 6-11.

Barlow, D. H. 2000. "Unraveling the Mysteries of Anxiety and Its Disorders from the Perspective of Emotion Theory." American Psychologist 55: 1247-63.

Booth, A. L., L. Cardona-Sosa, and P. Nolen. 2014. "Gender Differences in Risk Aversion: Do Single-Sex Environments Affect Their Development?" Journal of Economic Behavior and Organization 99: 126-54.

Bord, R. J., and R. E. O'Connor. 1997. “The Gender Gap in Environmental Attitudes: The Case of Perceived Vulnerability to Risk." Social Science Quarterly 78: 830-40.

Ciccia, R., and M. Verloo. 2012. "Parental Leave Regulations and the Persistence of the Male Breadwinner Model: Using Fuzzy-Set Ideal Type Analysis to Assess Gender Equality in an Enlarged Europe." Journal of European Social Policy 22 (5): 507-28.

Connell, R. W. 1995. Masculinities. Berkeley, CA: University of California Press.

Djerf-Pierre, M., and L. Wängnerud. 2016. "Gender and Sociotropic Anxiety: Explaining Gender Differences in Anxiety to Social Risks and Threats." International Journal of Public Opinion Research 28 (2): 217-40.

Dovidio, J. F., J. A. Piliavin, D. A. Schroeder, and L. Penner. 2006. The Social Psychology of Prosocial Behavior. Mahwah, NJ: Erlbaum.

Eagly, A. H. 2009. "The His and Her of Prosocial Behavior: An Examination of the Social Psychology of Gender." American Psychologist 64 (8): 644-58.

Eagly, A. H., and V. J. Steffen. 1984. "Gender Stereotypes Stem from the Distribution of Women and Men into Social Roles." Journal of Personality and Social Psychology 46 (4): $735-54$.

Edström, M., and M. Jacobsson. 2015. "Räkna med kvinnor" [Count on women]. Global Media Monitoring Project 2015. University of Gothenburg: JMG, Work report no. 73.

Egan, S. K., and D. G. Perry. 2001. "Gender Identity: A Multidimensional Analysis with Implications for Psychosocial Adjustment.” Development Psychology 37 (4): 451-63.

Ellemers, N. 2018. "Gender Stereotypes." Annual Review of Psychology. 69: 275-298.

Esarey, J., and G. Chirillo. 2013. "Fairer Sex’ or Purity Myth? Corruption, Gender and Institutional Context." Politics \& Gender 9 (4): 361-89.

Esarey, J., and L. Schwindt-Bayer. 2017. "Women's Representation, Accountability, and Corruption in Democracies." British Journal of Political Science, published online January 26, 2017.

Flynn, J., P. Slovic, and C. K. Mertz. 1994. "Gender, Race, and Perception of Environmental Health Risks." Risk Analysis 14: 1101-8.

Gill, S., J. Stockrad, M. Johnson, and S. Williams. 1987. "Measuring Gender Differences: The Expressive Dimension and Critique of Androgyny Scales." Sex Roles 17 (7): 375400. 
Gustafson, P. E. 1998. "Gender Differences in Risk Perception: Theoretical and Methodological Perspectives." Risk Analysis 18 (6): 805-11.

Hancock, A.-M. 2007. “When Multiplication Doesn’t Equal Quick Addition: Examining Intersectionality as a Research Program." Perspectives on Politics 5 (1): 63-79.

Hatemi, P. K., R. McDermott, J. M. Bailey, and N. G. Martin. 2012. "The Different Effects of Gender and Sex on Vote Choice." Political Research Quarterly 65 (1): 76-92.

Hoffman, R. M., and L. D. Borders. 2001. "Twenty-Five Years after the Bem Sex-Role Inventory: A Reassessment and New Issues Regarding Classification Variability." Measuring and Evaluation in Counseling and Development 34 (1): 39-55.

Hogg, M. A., D. J. Terry, and K. M. White. 1995. "A Tale of Two Theories: A Critical Comparison of Identity Theory with Social Identity Theory." Social Psychology Quarterly 58 (4): 255-69.

Hollander, J. A. 2001. "Vulnerability and Dangerousness: The Construction of Gender Through Conversation about Violence." Gender and Society 15: 83-109.

— 2002. "Resisting Vulnerability: The Social Reconstruction of Gender in Interaction." Social Problems 49: 474-96.

Huddy, L. 2001. "From Social to Political Identity: A Critical Examination of Social Identity Theory." Political Psychology 22 (1): 127-56.

Hunt, K., H. Lewars, C. Emslie, and G. D. Batty. 2007. "Decreased Risk of Death from Coronary Heart Disease Amongst Men with Higher 'Femininity' Scores: A General Population Cohort Study." International Journal of Epidemiology 36 (3): 612-20.

Lilliefeldt, E. 2012. "Party and Gender in Western Europe: A Fuzzy-Set Qualitative Comparative Analysis of Gender-Balanced Parliamentary Parties." Party Politics 18 (2): $193-214$.

Magliozzi, D., A. Saperstein, and L. Westbrook. 2016. "Scaling Up: Representing Gender Diversity in Survey Research." Socius (2): 1-11.

McLaughlin, H., C. Uggen, and A. Blackstone. 2012. "Sexual Harassment, Workplace Authority, and the Paradox of Power." American Sociological Review 7 (4): 624-47.

Mutz, D. C. 1994. “Contextualizing Personal Experience: The Role of Mass Media.” The Journal of Politics 56: 689-714.

Neuman, R. W., G. E. Marcus, A. N. Crigler, and M. MacKuen, eds. 2007. The Affect Effect: Dynamics of Emotion in Political Thinking and Behavior. Chicago: University of Chicago Press.

Niederle, M., and L. Vesterlung. 2007. "Do Women Shy Away from Competition? Do Men Compete Too Much?” Quarterly Journal of Economics 122 (3): 1067-1101.

Nilsson, A., and S. Holmberg. 2006. "Könsidentitet." In Nya gränser Västsverige, ed. L. Nilsson. Gothenburg: University of Gothenburg: Rapport 37, SOM Institute.

Palan, K. M., C. S. Areni, and P. Kiecker. 1999. "Reexamining Masculinity, Femininity, and Gender Identity Scales." Marketing Letters 10 (4): 363-77.

Satterfield, T. A., C. K. Mertz, and P. Slovic. 2004. "Discrimination, Vulnerability, and Justice in the Face of Risk." Risk Analysis 24: 115-29.

Slovic, P. 1999. "Trust, Emotion, Sex, Politics, and Science: Surveying the Risk-Assessment Battlefield." Risk Analysis 19: 689-701.

Swamy, A., S. Knack, Y. Lee, and O. Azfar. 2001. "Gender and Corruption." Journal of Development Economics 64 (1): 25-55.

Tauchert, A. 2002. "Fuzzy Gender: Between Female-Embodiment and Intersex." Journal of Gender Studies 11 (1): 29-38.

University of Gothenburg, SOM Institute. 2015. National SOM 2013. Version 1.0. Swedish National Data Service. http://dx.doi.org/10.5878/002630

Verge, T. 2012. "Institutionalising Gender Equality in Spain: From Party Quotas to Electoral Gender Quotas." West European Politics 35 (2): 395-414. 
Verge, T., M. Guinjoan, and T. Rodon. 2015. "Risk Aversion, Gender, and Constitutional Change." Politics \& Gender 11: 499-521.

Vernersdotter, F. 2014. "Den nationella SOM-undersökningen 2013." In Mittfåra \& marginal, eds. Annika Bergström and Henrik Oscarsson. Gothenburg: University of Gothenburg: SOM Institute. http://som.gu.se/digitalAssets/1487/1487725_531-560frida-vernersdotter-metod.pdf

Westbrook, L., and A. Saperstein. 2015. "New Categories Are Not Enough: Rethinking the Measurement of Sex and Gender in Social Surveys." Gender E Society 29 (4): 534-60. 